\title{
Exposure to HIV Risk and Utilization of HIV Post-Exposure Prophylaxis among Health Professionals of Governmental Health Institutions in Butajira Town, Southern, Ethiopia
}

\author{
Getamesay Mulatu*, and Siraj Hussen \\ School of Medical Laboratory Science, College of Medicine and Health Sciences, Hawassa University, Ethiopia
}

*Corresponding author: Getamesay Mulatu, School of Medical Laboratory Science, College of Medicine and Health Sciences, Hawassa University, Hawassa, Ethiopia, E-mail: get3bi@gmail.com

Received: 26 Oct, 2019 | Accepted: 13 Dec, 2019 | Published: 30 Dec, 2019

Citation: Mulatu G, Hussen S (2019) Exposure to HIV Risk and Utilization of HIV Post-Exposure Prophylaxis among Health Professionals of Governmental Health Institutions in Butajira Town, Southern, Ethiopia. J HIV AIDS 5(3): dx.doi.org/10.16966/2380-5536.171

Copyright: (C) 2019 Mulatu G, et al. This is an open-access article distributed under the terms of the Creative Commons Attribution License, which permits unrestricted use, distribution, and reproduction in any medium, provided the original author and source are credited.

\begin{abstract}
Objectives: The aim of this study was to assess exposure to Human Immunodeficiency Virus (HIV) risk and utilization of HIV Post Exposure Prophylaxis (PEP) among health workers of governmental health institutions in Butajira town, Southern, Ethiopia.

Methods: Cross-sectional study was conducted at Butajira Hospital and Health Center from July to September 2017. A total of 114 Health professionals were selected using simple random sampling technique. Socio-demography and associated factors was collected using structured questionnaires.

Result: Among health professionals enrolled in this study 71 (62.3\%) were nurses, 14 (12.3\%) midwives, 9 (7.9\%) physicians, 11 (9.6\%) laboratory technician/technologist, $8(7 \%)$ health officers and $1(0.9 \%)$ emergency surgeons. The observed rate of exposure to blood showed that $44.7 \%$, nonblood body fluid $37.7 \%$ and needle stick injury $42.7 \%$. Among exposed $6.9 \%$ were utilized PEP. The odds of PEP utilization was 8 times (COR=8.42, $95 \% \mathrm{Cl}=1.41-50.07)$ higher among those who trained on PEP than who did not trained.

Conclusion and Recommendation: The finding of this study indicates that, health professional in developing countries are highly exposed for blood and needle injury due to lack of safety system regulation in routine activities and in contrary only few of them are implement HIV PEP service. Therefore, health institution in such area needs to revise health worker safety regulation system in order to effectively integrate with routine activities. In addition all health workers need be regularly refreshing their knowledge of factors leads for exposure and exercise proper implementation following exposure.
\end{abstract}

Keywords: Post Exposure Prophylaxis; Health workers; Southern Ethiopia

Abbreviations: PEP-Post Exposure Prophylaxis; HIV-Human Immunodeficiency Virus

\section{Introduction}

Human Immunodeficiency Virus (HIV) is a pandemic health problem responsible for death of many people and increase occupational exposure of health workers. Based on 2012 global HIV/ AIDS report, 34 million peoples living with HIV/AIDS globally, about half do not know their status [1,2]. Ethiopia is one of the hardest hit countries by HIV/AIDS epidemic with the national HIV prevalence of $1.4 \%$ in adults [3].

Human Immunodeficiency Virus commonly transmitted through unprotected sexual intercourse, mother to child, sharing of sharp instruments and contact with infected body fluids [4]. The risk for occupational transmission varies with the type, severity of the exposure, source patient stage of disease, length of time of contact, potential port of entry, and presence of more virulent strains of virus. From research findings, the estimated risk for HIV transmission after injury through a needle .contaminated with HIV infected blood and after mucous membrane, exposure was $0.3 \%$ and $0.1 \%$ respectively $[1]$.

Post exposure prophylaxis (PEP) is components of post exposure management when accidental transmission of HIV occurs on health professionals. After occupational exposure to HIV, the patient from whom the potentially infectious materials (index patient) as well as the exposed person should undergo serological screening. When the serological status of the source patient not known or consent was not possible, prophylaxis should be considered if there are indications of possible infection [5]. Post exposure prophylaxis involves taking anti-HIV medications as soon as possible after the patient have been exposed to HIV to try to reduce the chance of becoming HIV positive [6].

Health Care Workers (HCWs) practicing in poor countries like Ethiopia are more exposed to HIV following occupational exposure 
and less likely to use PEP than those working in developed countries and have well equipped facilities [6]. In addition, diversified clinical activities including different procedures are conducted at a health center and hospital levels in the Ethiopian context, which makes occupational exposure a concern. So it's cleared the need to assess the use and associated factors of HCWs towards the PEP [3].

In Ethiopia several studies regarding on HIV/AIDS has been reported from different parts of the country. However, only few of them addressed the use and associated factors of health care workers towards the PEP. Particularly in Butajira town it has not been previously done. Thus, this study initiates to explore existing HIV post exposure prophylaxis utilization and associated factors among health professionals of governmental health institutions in Butajira town, Sothern Ethiopia.

\section{Methods}

\section{Study area, design and period}

A cross sectional study design was conducted at Butajira town, which is located about $135 \mathrm{~km}$ south west of Addis Ababa and 162 $\mathrm{km}$ from capital city of southern regional Hawassa. The study was conducted from July to September, 2017. Butajira town has one governmental hospital, and one health centers.

\section{Sample size determination and sampling technique}

The sample size was determined using single population proportion formula with the following assumptions; prevalence of PEP 19.6\%,
Confidence Interval of $95 \%$ and margin of error $5 \%$. The initial sample size was 243 and, since, the source population was less than 10,000 , correction factor will be used to estimate the final sample size required. The finally the total sample size was determined to be 114 . Health worker from different disciplines were selected using simple random sampling method.

\section{Data collection process}

A pre-tested and structured questionnaire was used to collect information on socio-demographic characteristics (age, profession, qualification, and educational level) and associated factors (risk of HIV infection, service year and training on PEP) of study participants. Data was collected by two nurses who were trained on PEP guideline.

Data analysis: Data entry and analysis was done using SPSS version 23 computer software. Data was summarized and presented in a descriptive measure such as a table, figures, and percent. Binary logistic regression was used to asses association between, sociodemographic characteristics and different associated factors. Odds ratio (or) and its corresponding 95\% Confidence Interval (CI) was calculated. In all cases, $\mathrm{p}$ value less than 0.05 was considered to be statistically significant.

\section{Ethical Consideration}

Ethical approval was obtained from the institutional review board of Hawassa College of health science. Permission to conduct the study was also obtained from the Butajira Hospital and Health Centers.

Table 1: Socio demographic characteristics of the respondents of governmental health institutions in Butajira town, Southern, Ethiopia, 2017.

\begin{tabular}{|c|c|c|c|c|}
\hline Variables & Category & Butajira General Hospital Number (\%) & Butajira Health Center Number (\%) & Total Number (\%) \\
\hline \multirow{3}{*}{ Age } & 20-29 years & $56(67.5)$ & $18(58.1)$ & $74(64.9)$ \\
\hline & $30-39$ years & $25(30.1)$ & $12(38.7)$ & $37(32.5)$ \\
\hline & 40-59 years & $2(2.4)$ & $1(3.2)$ & $3(2.6)$ \\
\hline \multirow{2}{*}{ Sex } & Male & $38(45.8)$ & $12(38.7)$ & $50(43.9)$ \\
\hline & Female & $45(54.2)$ & 19(61.2) & $64(56.1)$ \\
\hline \multirow{6}{*}{ Profession } & Nurses & $51(61.4)$ & $20(64.5)$ & $71(62.3)$ \\
\hline & Midwife & $10(12)$ & $4(12.9)$ & $14(12.3)$ \\
\hline & Laboratory professionals & $9(10.8)$ & $2(6.5)$ & $11(9.6)$ \\
\hline & Physicians & $9(10.8)$ & $0(0.0)$ & $9(7.9)$ \\
\hline & Health officer & $3(3.6)$ & $5(16.1)$ & $8(7)$ \\
\hline & Emergency surgeon & $1(1.2)$ & $0(0)$ & $1(0.9)$ \\
\hline \multirow{3}{*}{ Educational level } & Diploma & $32(38.6)$ & $24(77.4)$ & $56(49.1)$ \\
\hline & First degree & $49(59)$ & $7(22.6)$ & $56(49.1)$ \\
\hline & MSc/specialist & $2(2.4)$ & $0(0)$ & $2(1.8)$ \\
\hline \multirow{8}{*}{ Department } & Adult OPD & $7(8.4)$ & $9(29)$ & $16(14)$ \\
\hline & Pedi OPD/ward & $15(18.1)$ & $4(12.9)$ & 19(16.7) \\
\hline & Surgical ward & $12(14.5)$ & $0(0)$ & $12(10.5)$ \\
\hline & Medical ward & $11(13.3)$ & $1(3.2)$ & $12(10.5)$ \\
\hline & Gyn/Obs ward & $20(24.1)$ & $10(32.3)$ & $30(26.3)$ \\
\hline & Laboratory & $9(10.8)$ & $2(6.5)$ & $11(9.6)$ \\
\hline & ART/TB clinic & $3(3.6)$ & $0(0)$ & $3(2.6)$ \\
\hline & Emergency OPD & $6(7.2)$ & $5(16.1)$ & 11(9.6) \\
\hline \multirow{3}{*}{ Service year } & $<5$ years & $8(9.6)$ & $6(19.4)$ & $14(12.3)$ \\
\hline & $5-10$ years & $52(62.7)$ & $15(48.4)$ & $67(58.8)$ \\
\hline & $>10$ years & $23(27.7)$ & $10(32.3)$ & $33(28.9)$ \\
\hline
\end{tabular}

Citation: Mulatu G, Hussen S (2019) Exposure to HIV Risk and Utilization of HIV Post-Exposure Prophylaxis among Health Professionals of Governmental Health Institutions in Butajira Town, Southern, Ethiopia. J HIV AIDS 5(3): dx.doi.org/10.16966/2380-5536.171 
All participants were informed about the purpose and importance of the study.

\section{Results}

\section{Socio-demographic characteristics}

A total of 114 Health professionals in Butajira Hospital and Health Center were participated from July to September 2017. Eighty three (72.8\%) were from Hospital and 31(27.2\%) were from health center. Out of 114 study participants 64 (56.1\%) were female and 50 (43.9) were males. The age of the respondents ranged from 20 to 48 years with the mean age of 27.91years (+7.09 SD). Of the total respondents, $71(62.3 \%)$ were nurses, 14 (12.3\%) midwives, 9 (7.9\%)physicians, 11 (9.6\%) laboratory technician/technologist, 8 (7\%) health officers and $1(0.9 \%)$ were emergency surgeons (Table 1$)$.

\section{Occupational exposure}

Based on the previous history of exposure, 24 (21.1\%) of the respondents had exposed to needle stick injury. Of this, 14(12.3\%) was occurred among nurses followed by midwifery $5(4.4 \%)$ and similarly high exposure to body fluids was among nurses $48(42.1 \%)$ and $9(7.9 \%)$ midwifery (Table 2).

\section{Utilization of PEP by different groups}

Utilization of PEP in this study is $6.9 \%$ as show in table 3 below, the highest PEP usage was observed among in the age range of 4049 years and above $(33.3 \%$ ) followed by those within $30-39$ years old (5.7\%). And, based on marital status, $8.2 \%$ and $4.3 \%$ of married and single HCPs were used PEP for HIV infections, respectively. With regard to site of Educational level, 5.2\% of First degree was Used

Table 2: Health professional's exposure to HIV risk conditions of governmental health institution in Butajira town, Southern, Ethiopia, 2017.

\begin{tabular}{|c|c|c|c|c|}
\hline \multirow{3}{*}{ Profession } & \multicolumn{4}{|c|}{ HIV Risk Condition } \\
\hline & \multicolumn{2}{|c|}{ Needle stick } & \multicolumn{2}{|c|}{ Blood/body fluid } \\
\hline & Yes & No & Yes & No \\
\hline Nurse & $14(12.3 \%)$ & $57(50 \%)$ & $48(42.1 \%)$ & $23(20.2 \%)$ \\
\hline Midwife & $5(4.4 \%)$ & $9(7.9 \%)$ & $9(7.9 \%)$ & $5(4.4 \%)$ \\
\hline Health officer & $0(0 \%)$ & $8(7 \%)$ & $4(3.5 \%))$ & $4(3.5 \%)$ \\
\hline Physician & $3(2.6 \%)$ & $6(5.3 \%)$ & $5(4.4 \%)$ & $4(3.5 \%)$ \\
\hline Laboratory & $1(0.9 \%)$ & $10(8.8 \%)$ & $5(4.4 \%)$ & $6(5.3 \%)$ \\
\hline Emergency surgeon & $1(0.9 \%)$ & $0(0 \%)$ & $1(0.9 \%)$ & $0(0 \%)$ \\
\hline Total & 24 (21.1\%) & 90 (78.9\%) & 72 (63.2\%) & 42 (36.8\%) \\
\hline
\end{tabular}

Table 3: Bivariate analysis of socio demographic and behavioral factors associated PEP utilization of governmental health institution in Butajira town, Southern, Ethiopia, 2017

\begin{tabular}{|c|c|c|c|c|c|}
\hline Variable & Category & No (\%) Included in the study & No.(\%) use PEP & Crude OR $(95 \% \mathrm{Cl})$ & P-V \\
\hline \multirow{3}{*}{ Age } & $20-29$ years & $76(66.7)$ & $2(2.6)$ & $3.30(0.51-21.31)$ & 0.21 \\
\hline & 30-39 years & $35(30.7)$ & $2(5.7)$ & $11.0(0.67-178.64)$ & 0.09 \\
\hline & 40-49 years & $3(2.6)$ & $1(33.3)$ & 1 & \\
\hline \multirow{2}{*}{ Sex } & Male & $50(43.9)$ & $4(12.5)$ & $5.57(0.59-52.56)$ & 0.13 \\
\hline & Female & $64(56.1)$ & $1(2.5)$ & 1 & \\
\hline \multirow{3}{*}{ Educational level } & Diploma & $54(47.4)$ & $2(3.7)$ & $0.08(0.04-1.69)$ & 0.08 \\
\hline & First degree & $58(50.9)$ & $3(5.2)$ & $0.69(0.00-1.56)$ & 0.06 \\
\hline & MSc/specialist & $2(1.8)$ & 0 & 1 & \\
\hline \multirow{3}{*}{ Service year } & $<5$ years & $16(14.0)$ & $2(12.5)$ & $0.30(0.02-3.83)$ & 0.35 \\
\hline & $5-10$ years & $67(58.8)$ & $2(3.0)$ & $0.90(0.78-10.32)$ & 0.93 \\
\hline & $>10$ years & $31(27.2)$ & $1(3.2)$ & 1 & \\
\hline \multirow{2}{*}{ Risk of HIV infection } & Yes & $102(89.5)$ & $5(4.9)$ & $0.50(0.05-5.01)$ & 0.55 \\
\hline & No & $12(10.5)$ & 0 & 1 & \\
\hline \multirow{2}{*}{ Training on PEP } & Yes & $13(11.4)$ & $3(23.1)$ & $8.42(1.41-50.07)^{*}$ & 0.01 \\
\hline & No & $101(88.6)$ & $2(2.0)$ & 1 & \\
\hline \multirow{2}{*}{ Guideline on PEP } & Yes & $56(49.1)$ & $1(1.8)$ & $1.85(0.29-11.79)$ & 0.51 \\
\hline & No & $58(50.9)$ & $4(6.9)$ & 1 & \\
\hline
\end{tabular}

NB: *variable significant at $\mathrm{P}<0.05 ; \mathrm{Cl}$ : confidence interval; P-V: p-value 
HIV PEP. In bivariate analysis, the odds of PEP utilization were 8 times higher among those who trained on PEP when compared with those who were not trained on PEP $(\mathrm{COR}=8.42,95 \% \mathrm{CI}=1.41$ 50.07) (Table 3).

\section{Discussion}

In this study, utilization of HIV post-exposure prophylaxis among health professionals in Butajira town was (6.9\%). The use of HIV postexposure prophylaxis in current study was in agreement with results reported in Abuja Nigeria (6\%) [7]. Higher post-exposure prophylaxis use was also reported from Jimma Ethiopia [8], Gondor [9], Mekele Ethiopia (19.6\%) [10]. This difference may be due to study participants, the health care setting, the availability of PPE in health care facilities, and on the job training about infection.

This study detected high levels of occupational exposures. Ever needle stick and sharp injuries in the last year's $37.7 \%$ and $21.97 \%$ respectively. This was greater than the previous similar studies done in Addis Ababa Ethiopia [11]. But in contrary higher result reported from Italy [12]. This difference might be due to the difference in the settings and finding from similar research on high risk for occupational exposure.

In the current study, it was observed that training on post-exposure prophylaxis had significant association with the use of HIV postexposure prophylaxis where Health professionals who had training on post-exposure prophylaxis had 8.4 times (AOR 8.42 ; 95\% CI=1.4150.07, $\mathrm{P}=0.02$ ) higher use of HIV PEP than non-trained professionals.

This study also detected high level of exposure to blood and body fluids $(44.7,37.7 \%)$, respectively as compared to a research done Harare regional state and Dire Dawa administrative $(28.8 \%$, $20.2 \%)$ respectively [10] and also detected similar level of exposure, a research finding in Jimma zone Oromia region south west Ethiopia $(44.3 \%, 39.1 \%)$, respectively this may be due to the similarity in the study participants. The difference may be probably different in type of exposure in these settings, such as were needle stick injuries blood and body fluids.

In our study, we found that those respondents that took HIV PEP, 3 (60\%) had completed taking correctly, but the rest 2 (40\%) had failed to complete due to adverse effects of the drugs. The low uptake of PEP in our study was similar to reports from Uganda and Kenya $[13,14]$. But this finding was in line with the estimation of CDC (17$47 \%$ ) proportion of health professionals taking PEP after occupational exposure to HIV positive sources didn't complete a full 4 week course of therapy because of an inability to tolerate the drugs [15].

\section{Conclusion}

Lack of safety system regulation in routine activities of the study area leads health professionals for occupational exposures and risk of HIV. However, the practice available post exposure prophylaxis for HIV was low. Thus, health organization in such area needs to revise health worker safety regulation system in order to effectively integrate with routine activities. In addition all health workers need be regularly refreshing their knowledge of factors leads for exposure and avoid them from proper implementation following exposure.

\section{Limitation of the Study}

The potential Limitation of our study was first, it is questionnairebased cross-sectional study in which were lied completely on information provided by the respondents. Second we made our study only in governmental health institution.

\section{Declarations}

\section{Ethics approval and consent to participate}

Ethical clearance and approval were obtained from the Institutional Review Board of Hawassa Health Science College. All participants were informed about the purpose and importance of the study. To ensure the confidentiality of participants' information, code numbers were used instead of identifiers. To ensure the voluntary participation of the study participants, a written informed consent was obtained from all study subjects.

\section{Consent for Publication}

Not applicable.

\section{Availability of Data and Materials}

There is no remaining data and materials; all information is clearly presented in the main manuscript.

\section{Competing Interest}

The authors declare there is no competing interest.

\section{Funding}

No funding was obtained. But, Hawassa College of health science provided minimal finance to support this work.

\section{Authors' Contributions}

GM and SH designed the study; SH, and GM performed the statistical analyses, interpretation, contributed to the write-up and approved the final version of the manuscript.

\section{Acknowledgements}

The authors would like to thank Hawassa college of Health science for little financial support. The authors extend their appreciation to the four Health science colleges providing us all the support needed during data collection. The authors are also grateful to the study participants who took part in the study.

\section{References}

1. Bell DM, Cardo DM, Chiarello L, Kaplan JE, Martin LS, et al. (1998) Public Health Service guidelines for the management of health-care worker exposures to HIV and recommendations for postexposure prophylaxis. MMWR Recomm Rep 47: 1-28.

2. World Health Organization, International Labour Organization (2007)|" Post-exposure prophylaxis to prevent HIV infection: Joint WHO/ILO guidelines on post-exposure prophylaxis ("PEP)" to prevent HIV infection.WHO, Geneva, Switzerland.

3. Beyera GK, Chercos DH (2015) Post exposure prophylaxis uptake against exposure to HIV/AIDS risk factors in healthcare settings was very low. Int J Infect Control 11: 1-7.

4. Bartlett JG, Weber D (2012) Management of healthcare workers exposed to HIV. Up To Date version. 17.

5. Bagheri Nejad S, Allegranzi B, Syed SB, Ellis B, Pittet D (2011) Healthcare-associated infection in Africa: a systematic review. Bull World Health Organ 89: 757-765.

6. Central Statistical Agency, ORC Macro (2006) Ethiopia Demographic and Health Survey 2005. Addis Ababa, Ethiopia and Calverton, Maryland, USA: Central Statistical Agency and ORC Macro.

7. Owolabi RS, Alabi P, Ajayi S, Daniel O, Ogundiran A, et al. (2012) Knowledge and practice of post-exposure prophylaxis (PEP) against 
HIV infection among health care providers in a tertiary hospital in Nigeria. J Int Assoc Physicians AIDS Care (Chic) 11: 179-183.

8. Bosena Tebeje, Chernet Hailu (2010) Assessment of HIV postexposure prophylaxis use among health workers of governmental health institutions in Jimma Zone, Oromiya Region, Southwest Ethiopia. Ethiop J Health Sci 20: 55-64.

9. Mathewos B, Birhan W, Kinfe S, Boru M, Tiruneh G, et al. (2013) Assessment of knowledge, attitude and practice towards post exposure prophylaxis for HIV among health care workers in Gondar, North West Ethiopia. BMC public health 13: 508.

10. Gebreslase T, Buruh G (2014) HIV Post-Exposure Prophylaxis Use and Associated Factors among Health Professionals of Governmental Health Institutions in Mekelle Town, Tigray Ethiopia, Cross-Sectional Study. J AIDS Clin Res 5: 2.

11. Alemayehu T (2010) Assessment of health care workers occupational exposure to HIV and post-exposure prophylaxis (PEP) in health centers and hospitals of Addis Ababa, Ethiopia. Int J Infect Dis 14 e249.

12. Bandolier E (2003) Occupational exposure to hospital employees in Italian hospitals over 5.5 years. London: AstraZeneca group.

13. Alenyo R, Fualal J, Jombwe J (2009) Knowledge, attitude and practices of staffs towards post-exposure prophylaxis for HIV infection at Mulago Hospital in Uganda. East and Central African J Surg 14: 99-102.

14. Taegtmeyer M, Suckling R, Nguku P, Meredith C, Kibaru J, et al. (2008) Working with risk: occupational safety issues among healthcare workers in Kenya. AIDS care 20: 304-310.

15. Panlilio AL, Cardo DM, Grohskopf LA, Heneine W, Ross CS (2005) Updated US Public Health Service guidelines for the management of occupational exposures to HIV and recommendations for postexposure prophylaxis. MMWR Recomm Rep 54: 1-17. 